\title{
Spousal Support and Satisfaction with Healthcare Services as Moderators between Psychological Morbidity and Adherence to Diet in Type 2 Diabetes Patients
}

\author{
M. Graça Pereira, PhD \\ Gabriela Ferreira, MS \\ J. Cunha Machado, PhD
}

Objectives: This study analyzed the moderating role of partners' support and satisfaction with healthcare services in the relationship between psychological morbidity and adherence to diet in patients with type 2 diabetes (T2DM). Methods: Participants were 387 recently diagnosed T2DM patients that answered the following instruments: Revised Summary of Diabetes SelfCare Activities Measure, Hospital Anxiety and Depression Scales, Multidimensional Diabetes Questionnaire and Patient Satisfaction Questionnaire. Results: Partners' positive and negative support moderated the relationship between psychological morbidity and adherence to diet. Satisfaction with healthcare services also moderated the relationship between psychological morbidity and adherence to diet. Conclusions: Intervention programs to promote adherence to diet in patients with type 2 diabetes should focus on partners' support and patient satisfaction with healthcare services.

Key words: adherence, healthcare, partners, type 2 diabetes

Health Behavior \& Policy Review. 2014;1(3):278-289

DOI: http://dx.doi.org/10.14485/HBPR.1.4.3
$\mathrm{D}$ iabetes is an endocrinology disease arising from an abnormal increase in blood glucose. $^{1-3}$ As a disorder it has reached the dimension of being a significant public health problem. ${ }^{4}$ According to $\mathrm{WHO}^{3}$ there are 347 million of people now living with diabetes. A 2011 Portuguese study revealed that $12.7 \%$ of the population lives with diabetes in which $90 \%$ has type 2 diabetes and $26.5 \%$ pre-diabetes. $^{5}$

Patients with diabetes must perform self-care behaviors, including eating a healthy diet., ${ }^{3,-13}$ However, non-adherence to a healthy diet is common among patients with type 2 diabetes. ${ }^{14-17}$ Literature has suggested that patients are more likely to perform self-care behaviors such as taking medication instead of eating a healthy diet or participating in regular physical activity, because the latter requires a lifestyle change and more effort from the patient. ${ }^{14}$ Patients often show difficulties changing dietary habits (eg, consuming high-fat food) and integrating fruits and vegetables into their new healthy plan. ${ }^{18}$

Adhering to a healthy diet promotes the maintenance of appropriate body weight and optimal glycemic control, leading to the reduction of cardiovascular risk and mortality caused by diabetes. ${ }^{17,19,20}$ In fact, an association between dietary recommendations and lower levels of HbAlc has been found. ${ }^{21,22}$ Non-adherence to a diet plan can lead to a series of complications, ${ }^{1,8,23}{ }^{24}$ resulting in reduced quality of life. ${ }^{9} 25-27$

Literature has suggested several barriers regard-

M. Graça Pereira, Associate Professor, Department of Applied Psychology, University of Minho, Braga, Portugal. Gabriela Ferreira, Research Member in the Family Health and Disease Study Group, University of Minho, Braga, Portugal. J. Cunha Machado, Assistant Professor, Institute of Social Sciences, University of Minho, Braga, Portugal.

Correspondence Dr Pereira; gracep@psi.uminho.pt 
ing non-adherence to a healthy diet, such as food costs, lack of knowledge or understanding of the prescribed plan, negative emotions such as helplessness or frustration, stress leading to incorrect choices or food quantity, difficulty in planning meals, social events or eating out, and low family/spousal support. ${ }^{15,17,28-30}$ Patients also report that communication with health professionals and limited knowledge about diet, are barriers to diet adherence. ${ }^{17,30}$

Thomas, Jones, Scarinci, and Brantley ${ }^{31}$ found a prevalence of $36 \%$ of depressive and/or anxiety disorders in type 2 diabetes patients. This same study suggested that diabetes diagnosis was associated with the co-diagnosis of depressive and/or anxiety disorders. However, few other studies have confirmed such an association. ${ }^{31-34}$ Anxiety has been associated with poor metabolic control, ${ }^{35}$ and when anxiety is treated, a positive impact on patients' metabolic control has been found. ${ }^{36}$ An association between anxiety symptoms and poor adherence to health behaviors has been found particularly a relationship between less physical activity and poor glycemic control. ${ }^{37}$ Pandit et $\mathrm{al}^{38}$ also found an association between distress and lower adherence to medication, as well as higher HbAlc among patients with diabetes. Claude et $\mathrm{l}^{39}$ analyzed data from 414 individuals with diabetes and found higher health anxiety on recently diagnosed diabetes patients. Besides, there was an association between health anxiety and poor adherence to diet as well as fear of diabetes complications. Some studies also have suggested an association between depressive symptoms and poor diabetes self-care behaviors such as dietary recommendations, medication, and exercise. Literature has also suggested an association between depressive symptoms and poor adherence to $\operatorname{diet}^{25,40-42}$ particularly low consumption of fruits and vegetables, higher consumption of fats, ${ }^{41,43}$ an increased risk of hyperglycemia and poor metabolic control, and the development of severe complications and lower quality of life. . $^{41,44-51 .}$ However, Kruse et $\mathrm{al}^{32}$ found that depression was not associated with metabolic control. Therefore, results are controversial regarding the role of psychological morbidity, on adherence to diabetes.

Because depressed patients often feel hopeless, it is more difficult to adhere to a regimen such as the one required by diabetes. Depression often leads to social isolation; as a result, patients are less likely to benefit from family and friends' support regarding treatment adherence. Depression is also associated with changes in cognitive functioning, which interfere with patients' memory to follow medical prescriptions. $^{44}$

Studies have demonstrated that the quality of the marital relationship predicted adaptation to diabetes, in several dimensions. ${ }^{52}$ In fact, marital adjustment and marital support have been associated with better adaptation to diabetes, including treatment adherence, less negative impact and distress, as well as better quality of life. ${ }^{52-56}$ Partners' support is crucial because of the involvement of the partner in many patients' self-care behaviors. It has been suggested that spouses' support is important regarding diet, because the partner may help to buy, plan, and prepare meals, and remind the patient to take diabetes medication, monitor glucose levels, or carry out physical activity. ${ }^{57-59}$ A partner's supportive behaviors such as encouragement and praising are associated with better adherence to diet, medication, physical activity, and monitoring of blood glucose; non-supportive behaviors such as criticizing and nagging, on the other hand, have been associated with poor adherence to self-care behaviors. ${ }^{56,59-61}$

Patients' satisfaction with healthcare services is a complex and multi-factorial construct, often used to assess the quality of medical care. ${ }^{62-66}$ Literature has suggested a set of skills and behaviors associated with satisfaction with healthcare providers: good communication skills such as giving information about the disease and its treatment, encouraging patients to ask questions, and addressing patients' needs. ${ }^{62,65,67,68}$ Also, staff's interpersonal skills are an important feature, including caring and emotionally supporting the patient, at the time of diagnosis, as well as showing empathy for patients' experiences. ${ }^{62,68-71}$ Several studies have shown that patients' satisfaction with healthcare is associated with better adherence to self-care behaviors in diabetes. $^{64,66}$ However, there is some inconsistency regarding the association between patients' satisfaction with healthcare and diabetes outcomes as assessed by metabolic control (HbA1c levels). ${ }^{63,72-74}$ Patients who received diabetes education were more satisfied with healthcare delivery. ${ }^{66}$ Physicians' interpersonal skills have been associated with 
Table 1

Descriptive Statistics for Demographic Variables $(\mathrm{N}=387)$

\begin{tabular}{|c|c|c|c|c|}
\hline Continuous Measure & Min & Max & Mean & SD \\
\hline Age & 30 & 86 & 59.2 & 10.45 \\
\hline Marriage Duration (months) & 4 & 698 & 393.1 & 149.78 \\
\hline Categorical Measure & & & & $\%$ \\
\hline $\begin{array}{l}\text { Sex } \\
\text { Female } \\
\text { Male }\end{array}$ & & & & $\begin{array}{l}41.9 \\
58.1\end{array}$ \\
\hline $\begin{array}{l}\text { Marital Status } \\
\text { Married } \\
\text { Cohabitant } \\
\text { Unmarried }\end{array}$ & & & & $\begin{array}{r}99.0 \\
0.8 \\
0.2\end{array}$ \\
\hline $\begin{array}{l}\text { Family History of Diabetes } \\
\text { No } \\
\text { Yes }\end{array}$ & & & & $\begin{array}{l}39.0 \\
61.0\end{array}$ \\
\hline $\begin{array}{l}\text { Duration of Diagnosis } \\
\leq 6 \text { months } \\
7<\mathrm{x} \leq 12 \text { months }\end{array}$ & & & & $\begin{array}{l}59.8 \\
40.2\end{array}$ \\
\hline
\end{tabular}

better long-term psychological adjustment to diabetes. ${ }^{70}$ Studies also have shown that psychological distress is associated with patients' dissatisfaction with healthcare services. ${ }^{67,68}$

Based on the model of Liveneh ${ }^{75,76}$ a partner's support and satisfaction with care (contextual variables) were analyzed as moderators in the relationship between psychological morbidity (reaction to the illness) and adherence to diet (physical domain of quality of life). In fact, following the model, adjustment to a chronic illness includes the reaction to illness such as psychological morbidity, the process of adaptation, and the psychosocial results of this process regarding quality of life. In all these phases, contextual vari- ables play an important role as moderators or mediators. Therefore, it was expected that positive and negative partner support would moderate the relationship between psychological morbidity and adherence to diet. It also was hypothesized that satisfaction with healthcare services (communication/ information and interpersonal relationships) would moderate the relationship between psychological morbidity and adherence to diet.

\section{METHODS}

\section{Participants and Procedure}

This is a quantitative study with a transversal design. The sample consisted of patients with type 2 diabetes that were identified by their physicians

\begin{tabular}{|c|c|c|c|c|}
\hline \multicolumn{5}{|c|}{$\begin{array}{c}\text { Table } 2 \\
\text { Descriptive Statistics for Psychological Variables }\end{array}$} \\
\hline Measure & Min & Max & Mean & SD \\
\hline Adherence to Diet & 0 & 14 & 10.19 & 4.36 \\
\hline Psychological Morbidity & 0 & 37 & 9.96 & 7.73 \\
\hline Partners' Positive Support & 0 & 48 & 14.77 & 12.71 \\
\hline Partners' Negative Support & 0 & 24 & 9.19 & 7.62 \\
\hline Satisfaction with Communication/Information & 24 & 55 & 43.74 & 5.26 \\
\hline Satisfaction with Interpersonal Relationships & 34 & 65 & 52.44 & 5.99 \\
\hline
\end{tabular}


Table 3

Moderation Analysis for Positive Partner Support in the Relationship between Psychological Morbidity and Adherence to Diet

\begin{tabular}{|c|c|c|c|c|}
\hline Predictor & $\Delta \mathbf{R}^{2}$ & $\boldsymbol{\beta}$ & $\mathbf{t}$ & $\mathbf{p}$ \\
\hline Step 1 & .043 & & & \\
\hline Psychological morbidity & & -.142 & -2.805 & .005 \\
\hline \multirow[t]{2}{*}{ Positive partner support } & & .133 & 2.629 & .009 \\
\hline & & & & $\mathrm{R}^{2}$ adj. .038 \\
\hline Step 2 & .062 & & & \\
\hline Psychological morbidity & & -.123 & -2.441 & .015 \\
\hline Positive partner support & & .139 & 2.762 & .006 \\
\hline \multirow[t]{2}{*}{ Psychological morbidity $\times$ positive partner support } & & .139 & 2.778 & .006 \\
\hline & & & & $R^{2}$ adj. .054 \\
\hline
\end{tabular}

and contacted by the researchers if they met the inclusion criteria. The data was collected in Family Health Units and Health Care Centers of the Northern region of Portugal. Patients were assessed the day of their medical or nursing appointment. The evaluation took place in a single moment, and the patients were informed about confidentiality and the voluntary nature of their collaboration by signing an informed consent form. Patients and partners answered the questionnaires individually in a room provided by the healthcare unit for that purpose and in the presence of one of the researchers.

Diabetes patients in Portugal, in primary health care units, have on average, 4 appointments per year with their family physician as well as with their family nurse (every 3 months). The nurse provides patients with education regarding self-care behaviors particularly those that the patients are having more difficulty in incorporating in their lifestyle. Inclusion criteria included: being at least 18 years old; being diagnosed with type 2 diabetes no longer than 12 months; living with a partner; and taking only oral medication for diabetes. Because patients who take insulin have different treatment demands, in this particular study, only patients taking oral medications were included.

\section{Instruments}

The Revised Summary of Diabetes Self-Care Activi-

Table 4

Moderation Analysis for Negative Partner Support in the Relationship between Psychological Morbidity and Adherence to Diet

\begin{tabular}{|c|c|c|c|c|}
\hline Predictor & $\Delta \mathbf{R}^{2}$ & $\beta$ & $\mathbf{t}$ & $\mathbf{p}$ \\
\hline Step 1 & .026 & & & \\
\hline Psychological morbidity & & -.161 & -3.169 & .002 \\
\hline \multirow[t]{2}{*}{ Negative partner support } & & -.026 & -.507 & .612 \\
\hline & & & & $R^{2}$ adj. .021 \\
\hline Step 2 & .048 & & & \\
\hline Psych. morbidity & & -.139 & -2.737 & .006 \\
\hline Negative partner support & & -.015 & -.301 & .763 \\
\hline \multirow[t]{2}{*}{ Psychological morbidity $\mathrm{x}$ negative partner support } & & .150 & 2.950 & .003 \\
\hline & & & & $\mathbf{R}^{2}$ adj. .040 \\
\hline
\end{tabular}


Figure 1

Partners' Positive Support as Moderator in the Relationship between Psychological Morbidity and Adherence to Diet

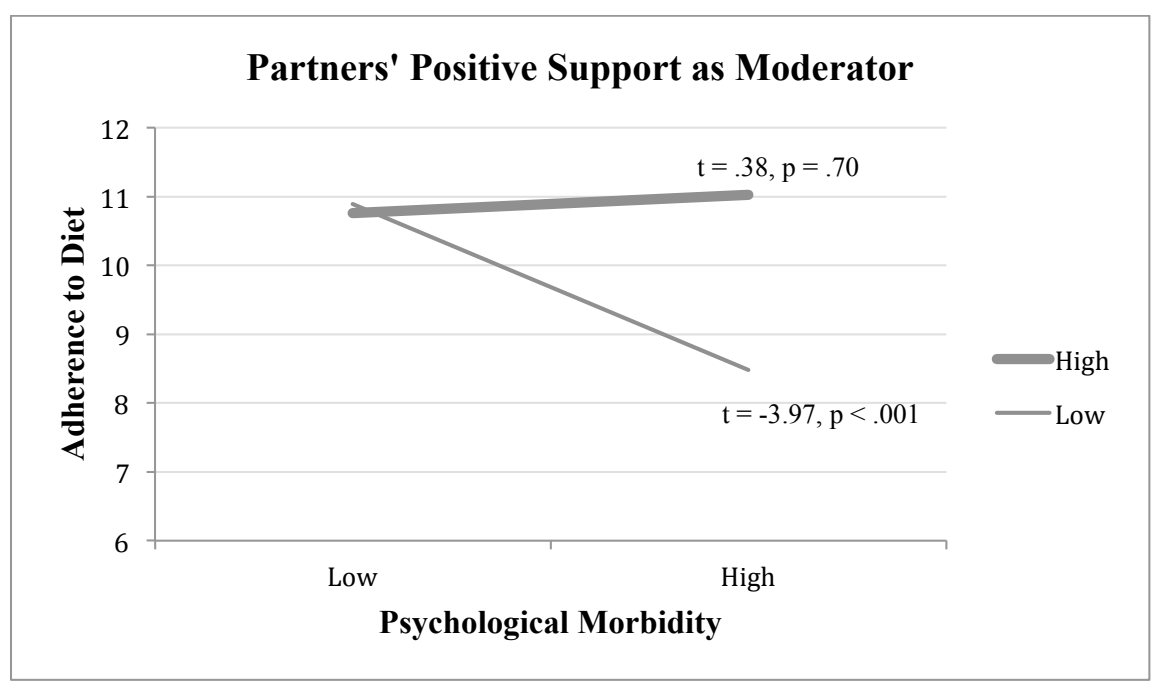

ties Measure (RSDSCA) ${ }^{13}$ assesses several components of diabetes self-care behaviors. It includes 11 items that assess adherence to diet, physical activity, glycemic control, foot care, and smoking. High scores indicate better adherence to the respective self-care behavior. The original version presents a Cronbach's alpha of .63 for the total scale that includes subscales that assess physical activity, foot care, glycemic control, and diet. ${ }^{76}$ In this study, only the general diet subscale was used because the

Figure 2

Partners' Negative Support as Moderator in the Relationship between Psychological Morbidity and Adherence to Diet

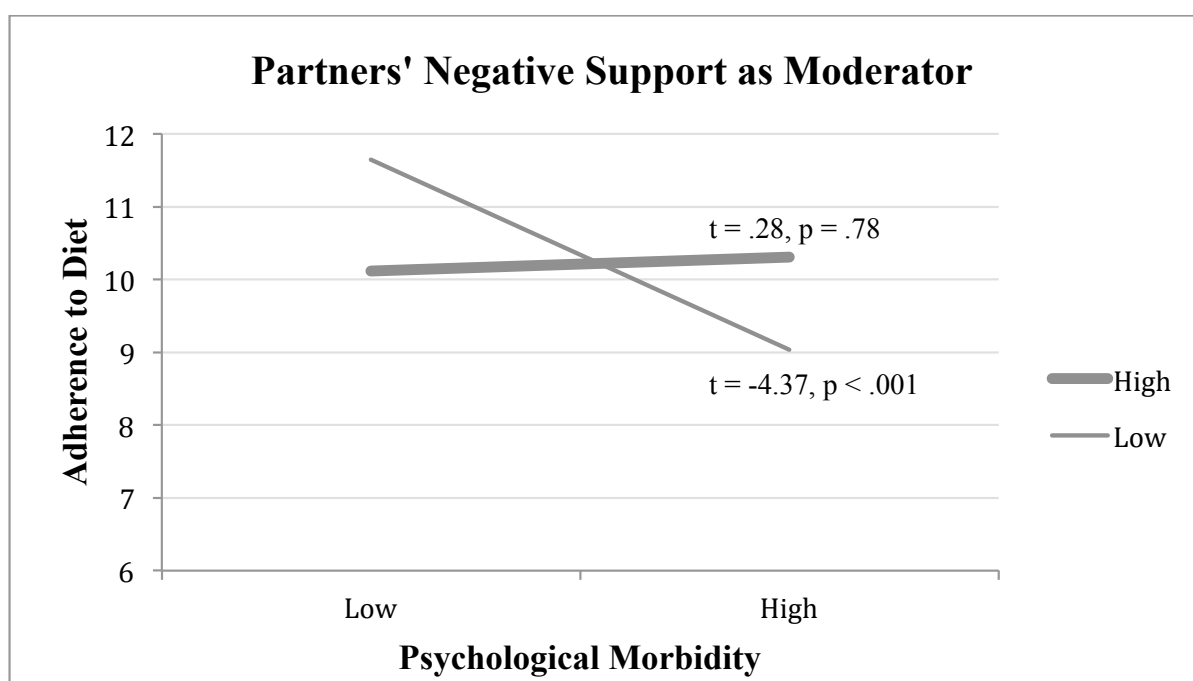


Table 5

Moderation Analysis for Satisfaction with Communication/Information in the Relationship between Psychological Morbidity and Adherence to Diet

\begin{tabular}{lcccc}
\hline Predictors & $\boldsymbol{\Delta} \mathbf{R}^{2}$ & $\boldsymbol{\beta}$ & $\mathbf{t}$ & $\mathbf{p}$ \\
\hline Step 1 & .028 & & & \\
Psychological morbidity & & -.155 & -3.043 & .003 \\
$\quad$ Satisfaction & & .047 & .931 & .353
\end{tabular}

$R^{2}$ adj. .023

Step 2

Psychological morbidity

Satisfaction

communication/information

Psychological morbidity $\mathrm{x}$

communication/information
.039

-.135
.033
.106

$-2.632$

.655

2.062
.009

.513

.040

$\mathbf{R}^{2}$ adj. .031

Cronbach's alpha was .95 and it presented a high fidelity. Due to the lower alpha of the specific diet subscale, it was not included in the hypothesis testing. The 2 item scores were summed to obtain a total score according to the instrument's instructions.

The Hospital Anxiety and Depression Scale $(H A D S)^{77}$ consists of 14 items divided into 2 subscales that assess anxiety and depression symptoms. Higher results indicate more symptoms of anxiety and/or depression. The Portuguese version ${ }^{78}$ showed a Cronbach's alpha of .89 for anxiety, .82 for depression, and .91 for the total scale. In this sample, Cronbach's alpha was .76 for the depression subscale, .78 for anxiety, and .85 for the total scale. In this study, only the total scale was used in the statistical analyses. The cut-off for clinical morbidity is 11 ; in this sample the mean was 9.96.

The original version of the Multidimensional Diabetes Questionnaire $(M D Q)^{79}$ consisted of 41 items organized in 3 sections evaluating cognitive and social factors related to diabetes. In the present study, only section II was used that consists of 12 items and assesses the frequency of partner support behaviors related to the different self-care behaviors patients have to perform (medication, diet, glucose self-monitoring, physical activity, and foot care). Supportive behaviors were categorized into positive reinforcing behaviors and misguided support behaviors; thus, higher results indicate higher levels of positive or negative support, respectively. In this study, Cronbach's alpha for positive support was .85 and .78 for negative support.

The Patient Satisfaction Questionnaire (QUA$S U)^{80}$ assesses patient satisfaction with healthcare services. The original version consists of 47 items plus one item of global assessment regarding health services, divided into 6 dimensions. In the present study, only the 26 items of the dimensions of communication/information and interpersonal relationships were used. The first subscale refers to the information given to patients by health professionals and the other scale evaluates aspects of the relationship with them such as empathy, respect, privacy, and confidence. Higher scores indicate more satisfaction in the respective dimension. In the original version, Cronbach's alpha was .87 for communication/ information and .81 for interpersonal relationships. ${ }^{80}$ In this sample, the alphas were of .87 for communication/ information and .91 for interpersonal relationships.

\section{Data Analysis}

Sample characteristics were analyzed for the variables under study. A Pearson correlation was used to determine if psychological morbidity was associated with adherence to diet. Moderation analysis using Baron and Kenny's ${ }^{81}$ method was performed to determine whether partners' positive and negative support were moderators of the relationship between psychological morbidity and adherence to diet, as well as whether satisfaction with 
Figure 3

Patients' Satisfaction with Communication and Information on Healthcare Services as Moderator in the Relationship between Psychological Morbidity and Adherence to Diet

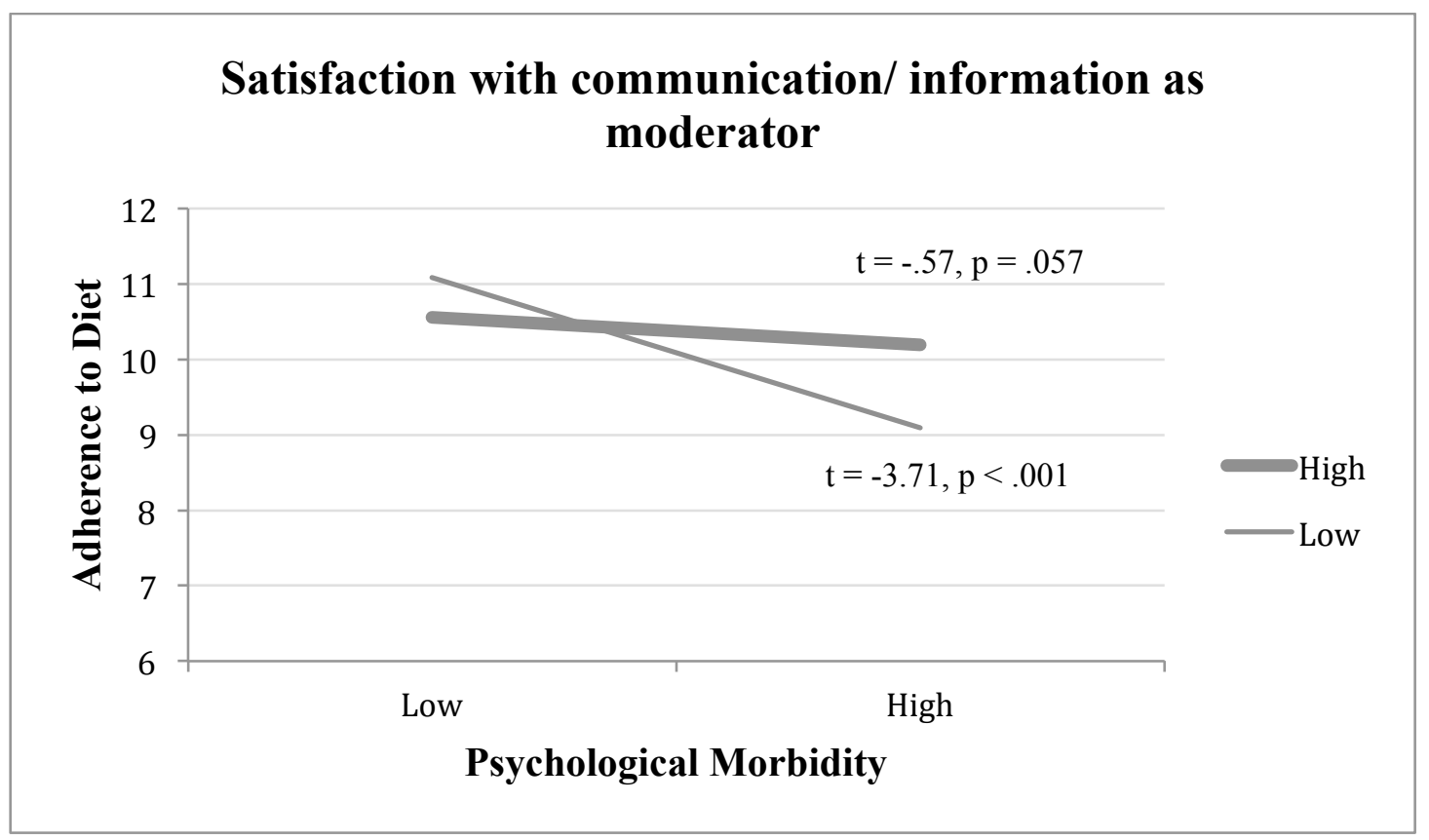

communication/ information and interpersonal relationships were moderators of the relationship between psychological morbidity and adherence to diet. This process includes a set of hierarchical regression analysis. Results were considered statistically significant at $\mathrm{p}<.05$. For the graphical display of statistical interactions regarding moderation, the ModGraph-I, version 3.0 was used. ${ }^{82}$

\section{RESULTS}

\section{Sample Characteristics}

This study included 387 patients with type 2 diabetes, diagnosed 12 months prior to the assessment. About $58 \%$ were males. The mean age was 59 years old $(\mathrm{SD}=10.41)$. Most of the patients were married or lived with a partner $(99.8 \%)$. The majority of the sample had 4 years of education (67.2\%). Table 1 shows the demographic characteristics of this sample. Table 2 presents the means and standard deviations for each psychological variable showing that this sample presents a high adherence to diet, low psychological morbidity, low partner support, and moderated satisfaction with healthcare services.

\section{Preliminary Analysis}

Psychological morbidity was negatively associated with adherence to diet $(\mathrm{r}=-.161, \mathrm{p}=.002)$. That is, the greater the number of psychological symptoms, the poorer the adherence to diet.

\section{Partners' Positive and Negative Support as Moderators in the Relationship between} Psychological Morbidity and Adherence to Diet

The hierarchical regression analysis revealed that the product of Partners' Positive and Negative Support versus Psychological Morbidity were predictors of adherence to diet (Table 3 and 4). Therefore, partners' positive and negative support are moderators in the relationship between psychological morbidity and adherence to diet (Figures 1 and 2, respectively). When partners' positive support $(\mathrm{t}=-3.97, \mathrm{p}<.001)$ or negative support $(\mathrm{t}=$ $-4.37, \mathrm{p}<.001)$ are low, the negative relationship between psychological morbidity and adherence to diet is stronger and, therefore, there is greater likelihood that patients adhere less to the prescribed diet (Figures 1 and 2). 
Table 6

Moderation Analysis for Satisfaction with Interpersonal Relationships in the Relationship between Psychological Morbidity and Adherence to Diet

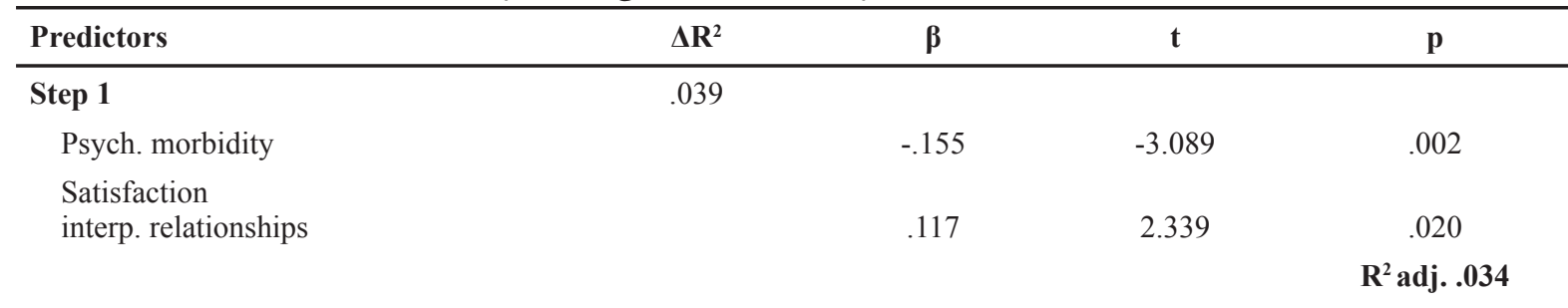

Step 2

Psychological morbidity

Satisfaction

interpersonal relationships

Psychological morbidity $\mathrm{x}$ interp. relationships
.051

\begin{tabular}{|c|c|c|}
\hline-.143 & -2.845 & .005 \\
\hline .105 & 2.096 & .037 \\
\hline \multirow[t]{2}{*}{.106} & 2.106 & .036 \\
\hline & & $R^{2}$ adj. .043 \\
\hline
\end{tabular}

Patients' Satisfaction with Communication and Information on Health Care Services as Moderators in the Relationship between Psychological Morbidity and Adherence to Diet

The hierarchical regression analysis revealed that the product of Patients' Satisfaction with Communication and Information versus Psychological Morbidity were predictors of adherence to diet (Table 5). Therefore, satisfaction with communication and information in healthcare services is a moderator in the relationship between psychological morbidity and adherence to diet (Figure 3). When patients' satisfaction is low $(\mathrm{t}=-3.71, \mathrm{p}<.001)$, the negative relationship between psychological morbidity and adherence to diet, is stronger; therefore, there is greater likelihood that patients will not adhere to the prescribed diet (Figure 3).

\section{Patients' Satisfaction with Interpersonal Relationships in Health Care Services as Moderator in the Relationship between Psychological Morbidity and Adherence to Diet}

The hierarchical regression analysis revealed that the product of Patients' Satisfaction with Interpersonal Relationships versus Psychological Morbidity were predictors of adherence to diet (Table 6). Therefore, satisfaction with interpersonal relationships, regarding healthcare services, is a moderator in the relationship between psychological morbid- ity and adherence to diet (Figure 4). So, when patients' satisfaction is low $(\mathrm{t}=-3.75, \mathrm{p}<.001)$, the negative relationship between psychological morbidity and adherence to diet is stronger; therefore, there is greater likelihood that patients will not adhere to the prescribed diet (Figure 4).

\section{DISCUSSION}

The aim of this study was to analyze whether partners' positive and negative support were moderators of the relationship between psychological morbidity and adherence to diet, as well as whether satisfaction with communication/ information and interpersonal relationships in healthcare services were moderators of the relationship between psychological morbidity and adherence to diet. The results revealed that patients who presented more psychological morbidity were less likely to adhere to a healthy diet. Other studies have found similar results. ${ }^{35,43-48}$ In patients newly diagnosed with type 2 diabetes, an association between depression and the diagnosis of type 2 diabetes has been found, and this result may be explained by the necessary lifestyle changes required after diagnosis. ${ }^{83,84} \mathrm{De}$ pression also can lead to functional cognitive deficits, which, in turn, can interfere with remember to follow medical regimens, ${ }^{44}$ explaining the importance of the moderating role of partners' support, by reminding the patient and reinforcing adher- 
Figure 4

Patients' Satisfaction with Interpersonal Relationships in Healthcare Services as Moderator in the Relationship between Psychological Morbidity and Adherence to Diet

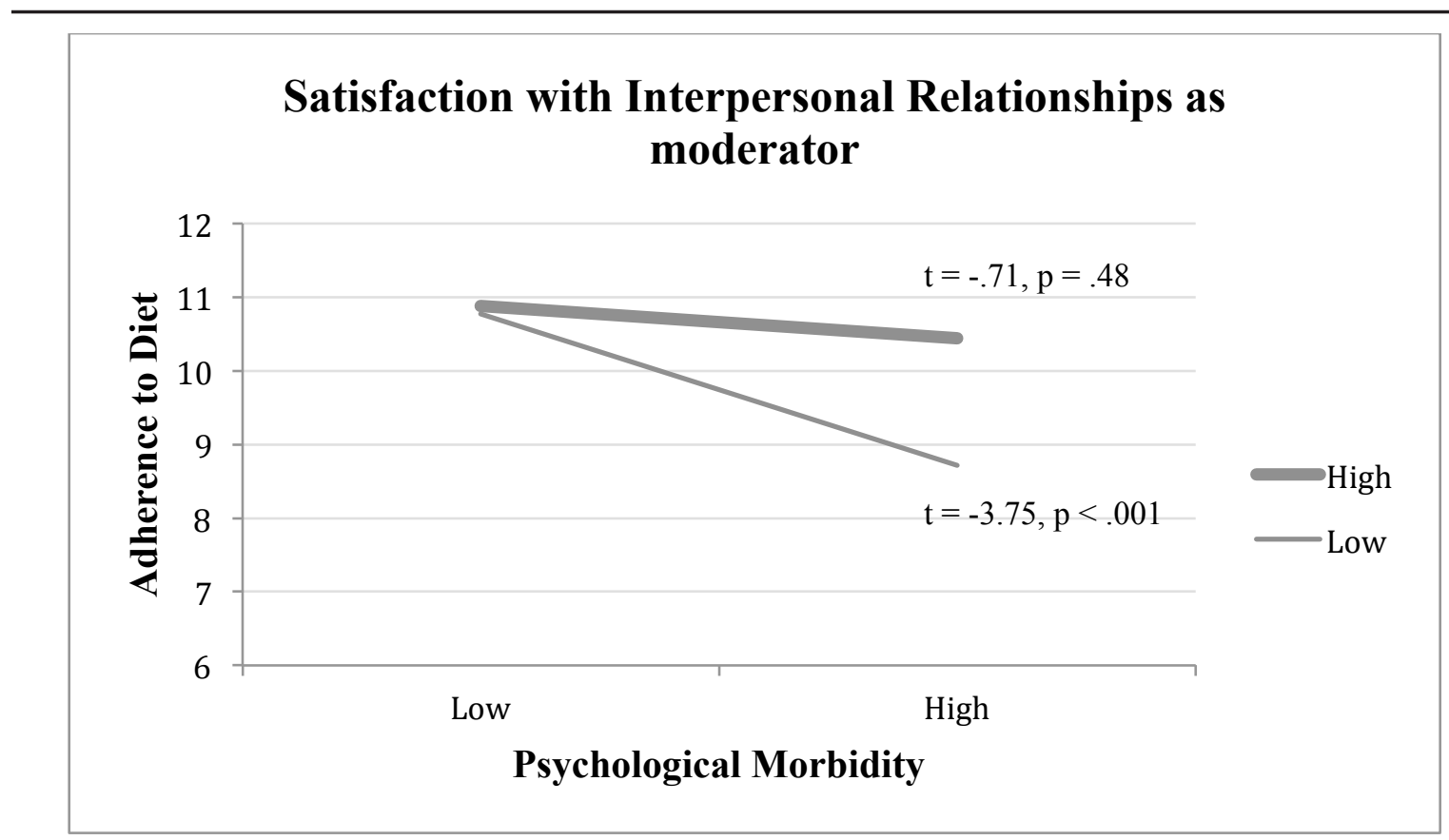

ence to self-care behaviors. In addition, studies also showed that social support protects patients with chronic diseases, from psychological distress, and is associated with less symptoms. ${ }^{47,85}$ Actually, the importance of partners' support to promote patients' adherence to type 2 diabetes treatment is well documented. ${ }^{56-61}$ Besides, studies differentiate the effects of both types of support, in which positive support has been associated with better adherence to self-care behaviors, and negative support has not. ${ }^{56,59-61}$ However, negative support was found to work as well as positive support regarding adherence to diet in type 2 Portuguese patients and the authors ${ }^{62}$ raised the hypothesis that patients may interpret negative support the same way as positive support, ie. being worried and concerned for the patient's health and wellbeing. In this study, when partners' positive and negative supports are low, patients with psychological morbidity are less likely to adhere to a healthy diet. Thus, psychological morbidity and partners' support seem crucial in patient adherence to diet. ${ }^{57-59}$

The present study also found that satisfaction with communication and information, as well as satisfaction with interpersonal relationships, in healthcare services, moderated the relationship between psychological morbidity and adherence to diet. Studies showed that communication and interpersonal skills are associated with better adherence ${ }^{63,65-70,72}$ and psychological adjustment to a chronic disease, ${ }^{71}$ whereas less support from health services has been considered a barrier to adherence to diet. ${ }^{17,29,30,86}$ Greater psychological morbidity also was associated with dissatisfaction with healthcare services, ${ }^{68,69}$ which can be explained by the fact that depressive and anxiety symptoms may interfere with patients' cognitive skills, making them less perceptive of their needs. This may be considered one explanation for patients not asking important questions regarding diabetes to their physician and, resulting in poorer adherence to treatment. ${ }^{68}$

This study has some limitations. First, we used only self-report measures. Moreover, we included only recently diagnosed patients and only patients taking oral medications for diabetes. This particular sample had on average 4 years of education, thereby making them less educated than other possible samples. For this geographic area and patient age, 
however, this level of education is not uncommon. Therefore, our study should be replicated with more educated patients, with insulin-dependent patients, and with patients having a longer disease history. Moreover, future studies should include patients whose adherence is poorer than what we had in this sample.

\section{IMPLICATIONS FOR HEALTH BEHAVIOR OR POLICY}

This study emphasizes the importance of psychological morbidity and partners' support and satisfaction with healthcare services regarding adherence to diet in type 2 diabetes. Future programs to promote adherence should include these dimensions as targets. As our results suggest, it may be relevant to include both patients and their partners in these programs. ${ }^{59}$ In addition, it is paramount that health professionals are aware of the importance of screening for depressive and anxiety symptoms in patients with type 2 diabetes, as these constructs appear to influence adherence to diet. Moreover, future studies should assess the importance of partners' support and satisfaction with care regarding adherence to other self-care behaviors, in diabetes, as well as their influence over the course of the disease.

\section{Acknowledgements}

This study was part of a research project funded by the Foundation for Science and Technology (FCT) of Portugal.

\section{Human Subjects Approval Statement}

This study was approved by the Portuguese Ethical Committee of the Northern Regional Health Administration (Proc. 05.09.Ces).

\section{References}

1. Deshpande AD, Harris-Hayes M, Schootman M. Epidemiology of diabetes and diabetes-related complications. Phys Ther. 2008;88(11):1254-1264.

2. Lisboa ME, Duarte R. Classificação e Diagnóstico da Diabetes. In: Duarte R, (eds). Diabetologia Clinica. Lisbon, Portugal: Lidel; 2002:25-42.

3. World Health Organization. Diabetes: Fact Sheet. Available at: http://www.who.int/mediacentre/factsheets/ fs312/en/index.html. Accessed January 15, 2013.

4. Valdez R. Detecting undiagnosed type 2 diabetes: family history as a risk factor and screening tool. J Diabetes Sci
Technol. 2009;3:722-726.

5. Portuguese Society of Diabetology. Diabetes: Facts and Numbers 2012. Annual Report of the National Diabetes Observatory Portugal (on-line). Available at: https:// www.dgs.pt/paginaRegesto.aspx?back=1id=24141.. Accessed March 11, 2013.

6. American Diabetes Association. Standards of medical care in diabetes. Diabetes Care. 2013;36:s11-s66.

7. Caldeira J, Osório I. Alimentação - Noçóes práticas. In: Duarte R. (eds). Diabetologia Clínica. Lisbon. Portugal: Lidel; 2002:79-88.

8. Cox DJ, Gonder-Frederick L. Major developments in behavioral diabetes research. J Consult Clin Psych. 1992;60:628-638.

9. Delamater AM. Improving patient adherence. Clin Diabetes. 2006;24(2):71-77.

10. Eves ND, Plotnikoff RC. Resistance training and type 2 diabetes. Considerations for implementation at the population level. Diabetes Care. 2006;29(8):1933-1941.

11. Geulayov G, Goral A, Muhsen K, et al. Physical inactivity among adults with diabetes mellitus and depressive symptoms: results from two independent national health surveys. Gen Hosp Psychiat. 2010;32(6):570-576.

12. Hu G, Tuomilehto J. Lifestyle and outcome among patients with type 2 diabetes. Int Congr Ser. 2007;1303:160171.

13. Toobert DJ, Hampson SE, Glasgow RE. The summary of diabetes self-care activities measure: results from 7 studies and a revised scale. Diabetes Care. 2000;23(7):943-950.

14. Gatt S, Sammut R. An exploratory study of predictors of self-care behaviors in persons with type 2 diabetes. Int J Nurs Stud. 2008;45:1525-1533.

15. Nagelkerk J, Reick K, Meengs L. Perceived barriers and effective strategies to diabetes self-management. $J A d v$ Nurs. 2006;54:151-158.

16. Serour M, Alqhenaei H, Al-Saaqabi S, et al. Cultural factors and patients' adherence to lifestyle measures. Br J Gen Pract. 2007;57:291-295.

17. Vijan S, Stuart NS, Fitzgerald JT, et al. Barriers to following dietary recommendations in type 2 diabetes. Diabet Med. 2005;22:32-38.

18. Savoca M, Miller C. Food selection and eating patterns: themes found among people with type 2 diabetes mellitus. J Nutr Educ. 2001;33(4):224-233.

19. Diabetes Control and Complications Trial Research Group. The effect of intensive treatment of diabetes on the development and progression of long-term complications in insulin-dependent diabetes mellitus. $N$ Engl J Med. 1993;329:977-1036.

20. UK Prospective Diabetes Study Group. Intensive bloodglucose control with sulphonylureas or insulin compared with conventional treatment and risk of complications in patients with type 2 diabetes. Lancet. 1998;352:837-853.

21. Delahanty LM, Halford BN. The role of diet behaviors in achieving improved glycemic control in intensively treated patients in the diabetes control and complications trial. Diabetes Care. 1993;16:1453-1458.

22. Savoca MR, Miller CK, Ludwig DA. Food habits are related to glycemic control among people with type 2 diabetes mellitus. J Am Diet Assoc. 2004;104:560-566.

23. Almeida J. Impact of psychological factors associated with therapeutic adherence, metabolic control and quality of 
life in adolescents with type 1 diabetes. Doctoral Dissertation. Braga, Portugal: University of Minho; 2003.

24. Colberg SR, Sigal RJ, Fernhall B, et al. Exercise and type 2 diabetes: the American College of Sports Medicine and the American Diabetes Association joint position statement. Diabetes Care. 2010;33(12):147-e167.

25. Ciechanowski PS, Katon WJ, Russo JE. Impact of depressive symptoms on adherence, function, and costs. Arch Intern Med. 2000;160:3278-3285.

26. Grant RW, Devita NG, Singer DE, Meigs JB. Polypharmacy and medication adherence in patients with type 2 diabetes. Diabetes Care. 2003;26(5):1408-1412.

27. Mårdby A, Åkerlind I, Jörgensen T. Beliefs about medicines and self-reported adherence among pharmacy clients. Patient Educ Couns. 2007;69:158-164.

28. Marcy TR, Britton ML, Harrison D. Identification of barriers to appropriate dietary behavior in low-income patients with type 2 diabetes mellitus. Diabetes Ther. 2011;2(1):9-19.

29. Schlundt DG, Hargreaves MK, Buchowski MS. The eating behavior patterns questionnaire predicts dietary fat intake in African American women. J Am Diet Assoc. 2003;103:338-345.

30. Uchenna O, Ijeoma E, Pauline E, Sylvester O. Contributory factors to diabetes dietary regimen non-adherence in adults with diabetes. World Acad Sci Eng Technol. 2010;45:735-742.

31. Thomas J, Jones G, Scarinci I, Brantley P. A descriptive and comparative study of the prevalence of depressive and anxiety disorders in low-income adults with type 2 diabetes and other chronic illnesses. Diabetes Care. 2003;26(8):2311-2317.

32. Kruse J, Schmitz N, Thefeld W. On the association between diabetes and mental disorders in a community sample: results from the German national health interview and examination survey. Diabetes Care. 2003;26(6):18411846.

33. Lloyd CE, Dyer PH, Barnett AH. Prevalence of symptoms of depression and anxiety in a diabetes clinic population. Diabetic Med. 2000;17(3):198-202.

34. Li C, Barker L, Ford ES, et al. Diabetes and anxiety in US adults: findings from the 2006 Behavioral Risk Factor Surveillance System. Diabetic Med. 2008;25(7):878-881.

35. Fisher L, Skaff MM, Mullan JT, et al. A longitudinal study of affective and anxiety disorders, depressive affect and diabetes distress in adults with Type 2 diabetes. Diabetic Med. 2008;25(9):1096-1101.

36. Grigsby AB, Anderson RJ, Freedland KE, et al. Prevalence of anxiety in adults with diabetes: a systematic review. $J$ Psychosom Res. 2002;53:1053-1060.

37. Kendzor DE, Chen M, Reininger BM, et al. The association of depression and anxiety with glycemic control among Mexican Americans with diabetes living near the U.S.-Mexico border. BMC Public Health; 2014;14:176.

38. Pandit AU, Bailey SC, Curtis LM, et al. Disease-related distress, self-care and clinical outcomes among lowincome patients with diabetes. J Epidemiol Community Health. 2014;68(6):557-564.

39. Claude JA, Hadjistavropoulos HD, Friesen L. Exploration of health anxiety among individuals with diabetes: prevalence and implications. J Health Psychol. 2014;19(2):312322.
40. Ciechanowski PS, Katon WJ, Russo JE, Hirsch IB. The relationship of depressive symptoms to symptom reporting, self-care and glucose control in diabetes. Gen Hosp Psychiatry. 2003;25:246-252.

41. Lin EH, Katon W, Von Korff M, et al. Relationship of depression and diabetes self-care, medication adherence, and preventative care. Diabetes Care. 2004;27:21542160.

42. Park HS, Hong YS, Lee HJ, et al. Individuals with type 2 diabetes and depressive symptoms exhibited lower adherence with self-care. J Clin Epidemiol. 2004;57:978-984.

43. Gonzalez JS, Safren SA, Cagliero E, et al. Depression, self-care, and medication adherence in type 2 diabetes relationships across the full range of symptom severity. Diabetes Care. 2007;30(9):2222-2227.

44. DiMatteo MR, Lepper HS, Croghan TW. Depression is a risk factor for noncompliance with medical treatment: meta-analysis of the effects of anxiety and depression on patient adherence. Arch Intern Med. 2000;160(14):21012107.

45. Fisher L, Chesla CA, Skaff MM, et al. Depression and anxiety among partners of European-American and Latino patients with type 2 diabetes. Diabetes Care. 2002;25(9):1564-1570.

46. Lustman PJ, Griffith LS, Clouse RE. Depression in adults with diabetes: results of 5-year follow-up study. Diabetes Care. 1988;11(8):605-612.

47. Moreira RO, Papelbaum M, Appolinario JC, et al. Diabetes mellitus e depressão: uma revisão sistemática. Arq Bras Endocrinol Metab. 2003;47(1):19-29.

48. Lustman PJ, Anderson RJ, Freedland KE, et al. Depression and poor glycemic control: a meta-analytic review of the literature. Diabetes Care. 2000:23(7):934-942.

49. Egede L, Zheng D. Independent factors associated with major depressive disorder in a national sample of individuals with diabetes. Diabetes Care 2003;26:104-111.

50. Katon W, Von Korff M, Ciechanowski P, et al. Behavioral and clinical factors associated with depression among individuals with diabetes. Diabetes Care 2004;27:914-920.

51. Groot M, Anderson R, Freedland KE, et al. Association of depression and diabetes complications: a meta-analysis. Psychosom Med. 2001;63:619-630.

52. Trief PM, Wade MJ, Britton KD, Weinstock RS. A prospective analysis of marital relationship factors and quality of life in diabetes. Diabetes Care. 2002;25(7):1154-1158.

53. Garay-Sevilla ME, Nara LE, Malacara JM, et al. Adherence to treatment and social support in patients with NIDDM. J Diabetes Complicat. 1995;9:81-86.

54. Trief PM, Himes CL, Orendorff R, et al. The marital relationship and psychosocial adaptation and glycemic control of individuals with diabetes. Diabetes Care. 2001;24(8):1384-1389.

55. Trief PM, Ploutz-Snyder R, Britton BA, Weinstock RS. The relationship between marital quality of life and adherence to the diabetes care regimen. Ann Behav Med. 2004;27:148-154.

56. Trief PM, Sandberg JG, Ploutz-Snyder R, et al. Promoting couples collaboration in type 2 diabetes: the diabetes support project pilot data. Fam Syst Health. 2011;29(3):253261.

57. Coyne JC, Smith DA. Couples coping with a myocardial infarction: a contextual perspective on patient self-effica- 
cy. J Fam Psychol. 1994;8:43-54.

58. Gopichandran V, Lyndon S, Angel MK, et al. Diabetes self-care activities: a community-based survey in urban southern India. Natl Med J India. 2012;25:14-17.

59. Trief PM, Sandberg J, Greenberg RP, et al. Describing support: a qualitative study of couples living with diabetes. Fam Syst Health. 2003;21(1):57-67.

60. Mayberry LS, Osborn CY. Family support, medication adherence, and glycemic control among adults with type 2 diabetes. Diabetes Care. 2012;35(6):1239-1245.

61. Stephens MAP, Rook KS, Franks MM, et al. Spouses use of social control to improve diabetic patients' dietary adherence. Fam Syst Health. 2010;28(3):199-208.

62. Pereira MG, Pedras S, Machado JC. Family variables as moderators between beliefs towards medicines and adherence to self-care behaviors and medication in type 2 diabetes. Fam Syst Health. 2014 Apr 7. [E pub ahead of print].

63. Ahmad I, Nawaz A, Khan S, et al. Predictors of patient satisfaction. Gomal J Med Sci. 2011;9:183-188.

64. Alazri MH, Neal RD. The association between satisfaction with services provided in primary care and outcomes in type 2 diabetes mellitus. Diabetic Med. 2003;20(6):486490.

65. Biderman A, Noff E, Harris SB, et al. Treatment satisfaction of diabetic patients: what are the contributing factors? Fam Pract. 2009;26(2):102-108.

66. Doubova SV, Pérez-Cuevas R, Zepeda-Arias M, FloresHernández S. Satisfaction of patients suffering from type 2 diabetes and/or hypertension with the care offered in family medicine clinics in Mexico. Salud Pública México. 2009;51(3):231-239.

67. Narayan KM, Gregg EW, Fagot-Campagna A, et al. Relationship between quality of diabetes care and patient satisfaction. J Natl Med Assoc. 2003;95:64-70.

68. Martino SC, Elliott MN, Kanouse DE, et al. Depression and the health care experiences of Medicare beneficiaries. Health Serv Res. 2011;46:1883-1904.

69. Shilling V, Jenkins V, Fallowfield L. Factors affecting patient and clinician satisfaction with the clinical consultation: can communication skills training for clinicians improve satisfaction? Psycho-Oncol. 2003;12(6):599-611.

70.Ali ES, Mahmoud EA. A study of patient satisfaction with primary health the care services in Saudi Arabia. $J$ Commun Health. 1993;18:49-54.

71. Mager WM, Andrykowski MA. Communication in the cancer 'bad news' consultation: patient perceptions and psychological adjustment. Psycho-Oncol. 2002;11(1):3546.

72. Ptacek JT, Ptacek JJ. Patients' perceptions of receiving bad news about cancer. J Clin Oncol. 2001;19:4160-4164.
73. Petterson T, Lee P, Hollis S, et al. Well-being and treatment satisfaction in older people with diabetes. Diabetes Care. 1998;21(6):930-935.

74. Redekop W, Koopmanschap M, Stolk R, et al. Healthrelated quality of life and treatment satisfaction in Dutch patients with type 2 diabetes. Diabetes Care. 2002;25(3):458-463.

75. Livneh H. Psychosocial adaptation to chronic illness and disability: a conceptual framework. Rehabil Couns Bull. 2001;44(3):151-160.

76. Livneh H, Antonak RF. Psychosocial adaptation to chronic illness and disability: a primer for counselors. J Couns Dev. 2005;83:12-20.

77.Zigmond AS, Snaith RP. The Hospital Anxiety and Depression Scale. Acta Psychiat Scand. 1983;67(6):361-370.

78. McIntyre T, Pereira MG, Soares V, et al. Escala de Ansiedade e de Depressão Hospitalar. Versão Portuguesa de Investigação. Universidade do Minho; 1999.

79. Talbot F, Nouwen A, Gingras J, et al. The assessment of diabetes related cognitive and social factors: the Multidimensional Diabetes Questionnaire. J Behav Med. 1997;20:291-312.

80. McIntyre T, Pereira MG, Silva NS, et al. Manual do Questionário de Avaliação da Satisfação do Utente. Porto: Administraçáo Regional de Saúde-Norte; 1999.

81. Baron RM, Kenny DA. The moderator-mediator variable distinction in social psychological research: conceptual, strategic, and statistical considerations. J Pers Soc Psychol. 1986;51(6):1173-1182.

82. Jose PE. ModGraph-I: A programme to compute cell means for the graphical display of moderational analyses: The Internet version, Version 3.0. Victoria University of Wellington, Wellington, New Zealand. Available at: http://pavlov.psyc.vuw.ac.nz/paul-jose/modgraph/. Accessed February 18, 2013.

83. Perveen S, Otho MS, Siddiqi MN, et al. Association of depression with newly diagnosed type 2 diabetes among adults aged between 25 to 60 years in Karachi, Pakistan. Diabetol Metab Syndr. 2010;2(17):1-6.

84. Yu R, Y-Hua L, Hong L. Depression in newly diagnosed type 2 diabetes. Int J Diabetes Dev Ctries. 2010;30(2):102104.

85. Thomas JL, Jones GN, Scarinci IC, Brantley PJ. Social support and the association of type 2 diabetes and depressive and anxiety disorders among low-income adults seen in primary care clinics. J Clin Psychol Med S. 2007;14(4):351-359.

86. Albarran NB, Ballesteros MN, Morales GG, et al. Dietary behavior and type 2 diabetes care. Patient Educ Couns. 2006;61:191-199. 